\title{
Laparoscopic R1 Vascular Hepatectomy for Hepatocellular Carcinoma (with Video)
}

\author{
Annarita Libia, $\mathrm{MD}^{1,2}$, Valentina Ferraro, $\mathrm{MD}^{2}$, Michele Tedeschi, $\mathrm{MD}$, $\mathrm{PhD}^{2}$, Nicola de'Angelis, $\mathrm{MD}, \mathrm{PhD}^{3}$, \\ Guido Torzilli, MD, $\mathrm{PhD}^{4}$, Luca Aldrighetti, $\mathrm{MD}, \mathrm{PhD}^{5}$, Patrick Pessaux, $\mathrm{MD}^{6}$, Daniel Cherqui, $\mathrm{MD}, \mathrm{PhD}^{7}$, and \\ Riccardo Memeo, MD, $\mathbf{P h D}^{8}$ \\ ${ }^{1}$ Department of Surgical Science, University of Rome La Sapienza, Rome, Italy; ${ }^{2}$ Department of Hepato-Biliary and \\ Pancreatic Surgery, Ecclesiastical Entity General Regional Hospital Francesco Miulli, Acquaviva delle Fonti, Italy; \\ ${ }^{3}$ Minimally invasive and Robotic Gastrointestinal Surgery, Acquaviva delle Fonti, Bari, Italy; ${ }^{4}$ Department of Surgery, \\ Division of Hepatobiliary and General Surgery, Humanitas Clinical and Research Center, Humanitas University, Milan, \\ Italy; ${ }^{5}$ Department of Surgery-Liver Unit, Scientific Institute San Raffaele, Milan, Italy; ${ }^{6}$ Hepato-Biliary Surgery and \\ Transplantation, Hautepierre Hospital, Strasbourg, France; ${ }^{7}$ Centre Hépato-Biliaire, AP-HP Hôpital Paul Brousse, \\ Villejuif, France; ${ }^{8}$ Department of Hepato-Pancreatic-Biliary Surgery, Miulli Hospital, Bari, Italy
}

\section{BACKGROUND}

Surgical resection is considered the standard of treatment for hepatocellular carcinoma (HCC), when realized with negative margins (R0) ${ }^{1}$. Not infrequently, R0 resection is unachievable, thus the concept of R1 vascular hepatectomy has been introduced and has been defined as exposure of the tumor on the specimen surface due to its detachment from vascular structures ${ }^{2-4}$.

\section{METHODS}

We present two cases of R1 vascular hepatectomy for HCC. The first patient was a 50-year-old male with a diagnosis of HCC in a chronic hepatitis $\mathrm{C}$ setting. The preoperative computed tomography scan showed a $30 \mathrm{~mm}$ HCC in segment $4 \mathrm{a}$, with a close relationship to the left hepatic vein, median hepatic vein, and vena cava. We

Supplementary information The online version of this article (h ttps://doi.org/10.1245/s10434-020-09582-4) contains supplementary material, which is available to authorized users.

(C) Society of Surgical Oncology 2021

First Received: 20 August 2020

Accepted: 24 December 2020

A. Libia, MD

e-mail: libiamd@me.com decided to perform an R1 vascular hepatectomy as a bridge to liver transplant. Surgery was performed using a cavitron ultrasonic surgical aspirator (CUSA), Aquamantys system, and Thunderbeat system, with an extracorporeal intermittent Pringle maneuver. The second patient was a 73-yearold male with a history of hepatitis $\mathrm{C}$ virus (HCV)-related liver disease. A $15 \mathrm{~mm}$ HCC was identified close to the right hepatic vein. A non-surgical approach with transarterial chemoembolization (TACE) was not possible due to stenosis of the celiac trunk, and the patient therefore underwent laparoscopic wedge resection of S7 (R1 vascular hepatectomy) using a CUSA and the Thunderbeat system, without the Pringle maneuver.

\section{RESULTS}

Operative time was 190 and $140 \mathrm{~min}$ for the first and second hepatectomies, respectively. No blood transfusion was necessary, and postoperative morbidity was nil. Both patients were discharged on postoperative day 3 .

\section{CONCLUSIONS}

Laparoscopic liver resection is now increasingly performed for HCC. R1 vascular hepatectomy for HCC is technically demanding but feasible and safe using the minimally invasive technique. 


\section{REFERENCES}

1. Zhong FP, Zhang YJ, Liu Y, Zou SB. Prognostic impact of surgical margin in patients with hepatocellular carcinoma: a metaanalysis. Medicine (Baltimore). 2017;96:e8043

2. Torzilli G, Donadon M, Cimino M. Are tumor exposure and anatomical resection antithetical during surgery for hepatocellular carcinoma? A critical review. Liver Cancer. 2012;1:177-82

3. Torzilli G, Montorsi M, Del Fabbro D, Palmisano A, Donadon M, Makuuchi M. Ultrasonographically guided surgical approach to liver tumours involving the hepatic veins close to the caval confluence. Br J Surg. 2006;93:1238-46

4. Donadon M, Terrone A, Procopio F, Cimino M, Palmisano A, Viganò $\mathrm{L}$, et al. Is R1 vascular hepatectomy for hepatocellular carcinoma oncologically adequate? Analysis of 327 consecutive patients. Surgery. 2019;165(5):897-904. https://doi.org/10.1016/j. surg.2018.12.002

Publisher's Note Springer Nature remains neutral with regard to jurisdictional claims in published maps and institutional affiliations. 